\title{
Regional lung aeration and ventilation during pressure support and biphasic positive airway pressure ventilation in experimental lung injury
}

\author{
Marcelo Gama de Abreu* †1, Maximiliano Cuevasł2, Peter M Spieth¹, Alysson R Carvalho', Volker Hietschold³, \\ Christian Stroszczynski³ ${ }^{3}$ Bärbel Wiedemann ${ }^{4}$, Thea Koch², Paolo Pelosi ${ }^{5}$ and Edmund Koch 6
}

\begin{abstract}
Introduction: There is an increasing interest in biphasic positive airway pressure with spontaneous breathing $\left(\mathrm{BIPAP}+\mathrm{SB}_{\text {mean }}\right)$, which is a combination of time-cycled controlled breaths at two levels of continuous positive airway pressure (BIPAP+SB $\left.B_{\text {controlled }}\right)$ and non-assisted spontaneous breathing (BIPAP+SB spont $_{1}$ ), in the early phase of acute lung injury (ALI). However, pressure support ventilation (PSV) remains the most commonly used mode of assisted ventilation. To date, the effects of BIPAP $+\mathrm{SB}_{\text {mean }}$ and PSV on regional lung aeration and ventilation during ALI are only poorly defined.

Methods: In 10 anesthetized juvenile pigs, ALI was induced by surfactant depletion. BIPAP+SB mean and PSV were performed in a random sequence ( $1 \mathrm{~h}$ each) at comparable mean airway pressures and minute volumes. Gas exchange, hemodynamics, and inspiratory effort were determined and dynamic computed tomography scans obtained. Aeration and ventilation were calculated in four zones along the ventral-dorsal axis at lung apex, hilum and base.

Results: Compared to PSV, BIPAP+SB mean resulted in: 1) lower mean tidal volume, comparable oxygenation and hemodynamics, and increased $\mathrm{PaCO}_{2}$ and inspiratory effort; 2) less nonaerated areas at end-expiration; 3) decreased tidal hyperaeration and re-aeration; 4) similar distributions of ventilation. During BIPAP+SB mean: i) $\mathrm{BIPAP}+\mathrm{SB} \mathrm{spont}_{\mathrm{t}}$ had lower tidal volumes and higher rates than $\mathrm{BIPAP}+\mathrm{SB}_{\text {controlled; }}$ ii) $\mathrm{BIPAP}+\mathrm{SB}_{\text {spont }}$ and $\mathrm{BIPAP}+\mathrm{SB}$ controlled had similar distributions of ventilation and aeration; iii) $\mathrm{BIPAP}+\mathrm{SB}_{\text {controlled }}$ resulted in increased tidal re-aeration and hyperareation, compared to PSV. BIPAP+SB spont showed an opposite pattern.

Conclusions: In this model of ALI, the reduction of tidal re-aeration and hyperaeration during BIPAP+SB $B_{\text {mean }}$ compared to PSV is not due to decreased nonaerated areas at end-expiration or different distribution of ventilation, but to lower tidal volumes during $\mathrm{BIPAP}+\mathrm{SB}_{\text {spont }}$. The ratio between spontaneous to controlled breaths seems to play a pivotal role in reducing tidal re-aeration and hyperaeration during $\mathrm{BIPAP}+\mathrm{SB}_{\text {mean }}$.
\end{abstract}

\section{Introduction}

Maintenance of spontaneous breathing activity during ventilatory support in acute lung injury (ALI) may improve pulmonary gas exchange, systemic blood flow, and oxygen

* Correspondence: mgabreu@uniklinikum-dresden.de

1 Pulmonary Engineering Group, Department of Anaesthesiology and Intensive Care Therapy, University Hospital Carl Gustav Carus, Technical University of Dresden, Fetscherstr. 74, 01307 Dresden, Germany + Contributed equally

Full list of author information is available at the end of the article supply to the tissues [1]. Most importantly, spontaneous breathing activity may contribute to decrease the time of ventilatory support and the length of stay in the intensive care unit [2]. Although pressure support ventilation (PSV) is the most frequently used form of assisted mechanical ventilation [3], there is increasing interest in biphasic positive airway pressure with superposed spontaneous breathing $\left(\mathrm{BIPAP}+\mathrm{SB}_{\text {mean }}\right)$ [4]. PSV is a pressure-limited, flowcycled mode in which every breath is supported by a con-

( 2010 Gama de Abreu et al.; licensee BioMed Central Ltd. This is an open access article distributed under the terms of the Creative BHoWed Central Commons Attribution License (http://creativecommons.org/licenses/by/2.0), which permits unrestricted use, distribution, and reproduction in any medium, provided the original work is properly cited. 
stant level of pressure at the airways, thus the tidal volume $\left(\mathrm{V}_{\mathrm{T}}\right)$ and inspiratory flow may adapt to the demands of the patient [5]. In contrast, $\mathrm{BIPAP}+\mathrm{SB}_{\text {mean }}$ is a combination of time-cycled controlled breaths at two levels of continuous positive airway pressure (BIPAP $\left.+\mathrm{SB}_{\text {controlled }}\right)$ and nonassisted spontaneous breathing (BIPAP+SB $\left.{ }_{\text {spont }}\right)$ [4]. Compared with controlled mechanical ventilation and PSV, a possible advantage of non-assisted spontaneous breath during $\mathrm{BIPAP}+\mathrm{SB}_{\text {mean }}$ is that they may generate higher transpulmonary pressures in dependent lung areas, contributing to lung recruitment, reduction of cyclic collapse/reopening and improvement of ventilation/perfusion matching [6-8].

Previous studies comparing PSV with $\mathrm{BIPAP}+\mathrm{SB}_{\text {mean }}$ have not assessed the distribution of both aeration and ventilation $[6,9,10]$. In experimental ALI, we observed that aeration compartments of the whole lungs did not differ between $\mathrm{BIPAP}+\mathrm{SB}_{\text {mean }}$ or PSV and controlled mechanical ventilation [11]. In contrast, Yoshida and colleagues [10] suggested that, in patients with ALI, improvement of lung aeration is more pronounced during $\mathrm{BIPAP}+\mathrm{SB}_{\text {mean }}$ than PSV. However, both in an animal [11] and patient study [10], aeration was assessed at end-expiration with static computed tomography (CT) during breath holding, possibly introducing artifacts. As dynamic $\mathrm{CT}\left(\mathrm{CT}_{\mathrm{dyn}}\right)$ does not require breath holding, it may be considered a suitable technique for assessing lung aeration and ventilation during $\mathrm{BIPAP}+\mathrm{SB}_{\text {mean }}$ and PSV.

In the current study, we investigated the distributions of regional aeration and ventilation at the lungs' apex, hilum and base during PSV and BIPAP+SB ${ }_{\text {mean }}$ using $\mathrm{CT}_{\text {dyn }}$ in experimental ALI. We hypothesized that $\mathrm{BIPAP}+\mathrm{SB}_{\text {mean }}$, compared with PSV: is associated with decreased amounts of nonaerated lung tissue and increased relative ventilation in dorsal lung zones due to increased inspiratory effort; and decreases tidal reaeration and hyperaeration through reduction of nonaerated lung tissue and different distribution of ventilation.

\section{Materials and methods}

The protocol of this study has been approved by the local animal care committee and the Government of the State Saxony, Germany. Ten pigs (weighing 25.0 to $36.5 \mathrm{~kg}$ ) were pre-medicated and anesthetized with intravenous midazolam, ketamine, and remifentanil. The trachea was intubated and lungs were ventilated with an EVITA XL 4 Lab (Dräger Medical AG, Lübeck, Germany) in the volume-controlled mode using a $\mathrm{V}_{\mathrm{T}}$ of $12 \mathrm{ml} / \mathrm{kg}$, inspiratory: expiratory ratio (I:E) of $1: 1$, fraction of inspired oxygen $\left(\mathrm{FiO}_{2}\right)$ of 0.5 , positive end-expiratory pressure (PEEP) of 5 $\mathrm{cmH}_{2} \mathrm{O}$, and respiratory rate (RR) set to achieve normocapnia. We decided to use a PEEP of $5 \mathrm{cmH}_{2} \mathrm{O}$ to allow a better differentiation of tidal recruitment/reaeration and tidal hyperaeration between the modes investigated. Previous data from our group [12] suggest that such phenomena occur simultaneously but in different proportions depending on the level of PEEP. A FiO 2 of 0.5 was chosen to allow adequate oxygenation without increasing atelectasis. $\mathrm{FiO}_{2}$ and PEEP were not changed during the experiments. An esophageal catheter (Erich Jaeger GmbH, Höchberg, Germany) was advanced through the mouth into the mid chest. A crystalloid solution (E153, Serumwerk Bernburg AG, Bernburg, Germany) at a rate of 10 to $20 \mathrm{~mL} \cdot \mathrm{kg}^{-1} \cdot \mathrm{h}^{-1}$ was used to maintain volemia.

Hemodynamics was monitored with catheters placed in right external carotid and pulmonary arteries. Arterial and mixed venous blood samples were analyzed.

Airway flow, airway pressure $\left(\mathrm{P}_{\mathrm{aw}}\right)$ and esophageal pressure were measured using calibrated flow and pressure sensors placed at the endotracheal tube, and respiratory parameters calculated. The ratio of inspiratory to total respiratory cycle (Ti/Ttot) was also determined. The product of inspiratory esophageal pressure vs. time (PTP), the difference between $\mathrm{P}_{\mathrm{aw}}$ at the beginning of inspiration and $100 \mathrm{~ms}$ thereafter $\left(\mathrm{P}_{0.1}\right)$, and the dynamic intrinsic PEEP $\left(\mathrm{PEEP}_{\mathrm{i}, \text { dyn }}\right)$ were determined. Values of PTP, $\mathrm{P}_{0.1}$ and $\mathrm{PEEP}_{\mathrm{i}, \mathrm{dyn}}$ were taken from two minute and four minute recordings during controlled and assisted mechanical ventilation, respectively.

Respiratory parameters were computed from controlled $\left(\mathrm{BIPAP}+\mathrm{SB}_{\text {controlled }}\right)$ and spontaneous $\left(\mathrm{BIPAP}+\mathrm{SB}_{\text {spont }}\right)$ breath cycles. The contributions of spontaneous and controlled breaths to $\mathrm{BIPAP}+\mathrm{SB}_{\text {mean }}$ were weighted by their respective rates (weighted mean $\mathrm{BIPAP}+\mathrm{SB}_{\text {mean }}$ ). Mean airway and transpulmonary pressures were weighted also by time, that is as the integral of the area under the flow curve divided by time, as shown in detail in Additional file 1 .

\section{Dynamic computed tomography}

$\mathrm{CT}_{\mathrm{dyn}}$ measurements were performed with a Somatom Sensation 16 (Siemens, Erlangen, Germany) at three different lung levels: apex (about $3 \mathrm{~cm}$ cranial to the carina); hilum (at carina level); base (about 2 to $3 \mathrm{~cm}$ caudal to the carina). Scans were obtained every $120 \mathrm{~ms}$ during a period of 60 seconds, resulting in approximately 500 images per level. Each image obtained corresponded to a matrix with $512 \times$ 512 voxels of $0.443 \times 0.443 \times 1 \mathrm{~mm}^{3}$. Segmentation of the region of interest contained between the boundaries defined by the rib cage and mediastinal organs was performed semiautomatically, with software (CHRISTIAN II, Technical University Dresden, Germany) developed by one of the authors (MC). Each level was further divided into four zones of equal heights from ventral to dorsal $(1=$ ventral, 2 $=$ mid-ventral, $3=$ mid-dorsal, and $4=$ dorsal). The four zones had equal height at each different level (apex, hilus, and base). 
Aeration compartments at end-expiration and end-inspiration were computed based on an arbitrary scale for attenuation described elsewhere [13]. Accordingly, ranges of 1000 to -900 Hounsfield units (HU), -900 to $-500 \mathrm{HU},-500$ to $-100 \mathrm{HU}$, and -100 to $+100 \mathrm{HU}$ were used to define the hyperaerated, normally aerated, poorly aerated, and nonaerated compartments, respectively.

Tidal reaeration was calculated as the decrease in the percentage of nonaerated and poorly aerated compartments from end-expiration to end-inspiration [14]. Tidal hyperaeration was calculated as the increase in the percentage of hyperaeration from end-expiration to end-inspiration [14].

Ventilation in one zone of a given level was computed as the variation of gas content between end-inspiration and end-expiration of that zone divided by the total variation of gas content in the respective level.

For $\mathrm{BIPAP}+\mathrm{SB}_{\text {mean }}$, $\mathrm{CT}$ variables were computed in the same way as for respiratory parameters, that is weighted means of spontaneous and controlled breaths.

\section{Protocol for measurements}

After preparation, animals were allowed to stabilize for 15 minutes (baseline, volume-controlled mode). ALI was induced by means of surfactant depletion [15] and considered stable if partial pressure of oxygen $\left(\mathrm{PaO}_{2}\right) / \mathrm{FiO}_{2}$ was $200 \mathrm{mmHg}$ or less for at least 30 minutes (injury, volumecontrolled mode). After obtaining the measurements at injury, $\mathrm{BIPAP}+\mathrm{SB}_{\text {controlled }}$ was initiated as follows: the driving pressure, which corresponded to the difference between the higher and the lower continuous positive $\mathrm{P}_{\mathrm{aw}}$ level of 5 $\mathrm{cmH}_{2} \mathrm{O}$, was set to obtain $\mathrm{V}_{\mathrm{T}}$ of 7 to $8 \mathrm{ml} / \mathrm{kg}$ and mechanical RR was set to reach partial pressure of carbon dioxide $\left(\mathrm{PaCO}_{2}\right)$ in the range of 50 to $60 \mathrm{mmHg}$, without spontaneous breathing. The I:E ratio was set to achieve mean $\mathrm{P}_{\mathrm{aw}}$ in the range of 8 to $10 \mathrm{cmH}_{2} \mathrm{O}$, as expected in PSV. At the same time, depth of anesthesia was a reduced, remaining constant thereafter. Lower mechanical RR combined with reduced depth of anesthesia enabled spontaneous breathing (unsynchronized and superimposed to $\mathrm{BIPAP}+\mathrm{SB}_{\text {controlled}}$ ). When spontaneous breathing represented $20 \%$ or more of total minute ventilation, all animals were subjected to $\mathrm{BIPAP}+\mathrm{SB}_{\text {mean }}$ and $\mathrm{PSV}$ in randomized sequence for 60 minutes. During BIPAP $+\mathrm{SB}_{\text {mean }}$, the initial ventilatory settings of $\mathrm{BIPAP}+\mathrm{SB}_{\text {controlled }}$ were kept unchanged and spontaneous breathing efforts and rate increased according to the respiratory drive of the animals, without pressure support. During PSV, the target pressure support was set to achieve $\mathrm{V}_{\mathrm{T}}$ of 7 to $8 \mathrm{ml} / \mathrm{kg}$, the inspiratory flow trigger was fixed at $2.0 \mathrm{~L} / \mathrm{min}$ and the ventilator cycled-off at $25 \%$ of peak flow. Each assisted mechanical ventilation mode lasted 60 minutes. Measurements were performed at the following steps: baseline, injury and at the end of each assisted mechanical ventilation mode. The time elapsed between stabilization of injury, and first and second assisted mechanical ventilation mode corresponded to 60 and 120 minutes, respectively.

\section{Statistics}

Data are given as mean \pm standard deviation. Changes in functional variables were tested with two-tailed student's paired t-tests. Variables derived from $\mathrm{CT}_{\mathrm{dyn}}$ measurements were evaluated with mixed linear models using the following factors: level (apex, hilum, and base), zone (1 to 4) and type of mechanical ventilation (PSV, BIPAP $+\mathrm{SB}_{\text {mean }}$, $\mathrm{BIPAP}+\mathrm{SB}_{\text {controlled }}$ and $\left.\mathrm{BIPAP}+\mathrm{SB}_{\text {spont }}\right)$. Compound symmetry for the measures on the same animal was assumed. Identical correlations were also assumed and their strength was estimated by components of variance. Residuals were checked for normal distribution, as suggested by their plots. Final mixed linear models resulted from stepwise model choices and included only statistical significant effects. Multiple comparisons were adjusted by the Bonferroni procedure. Univariate and multivariate analysis were performed with the software SPSS (Version 15.0, Chicago, IL, USA) and SAS (Procedure Mixed, Version 8, SAS Institute Inc, Cary, NC, USA), respectively. Statistical significance was accepted at $P<0.05$ in all tests.

\section{Results}

\section{Induction of acute lung injury}

ALI was achieved with one to five lavages (median $=2.5$ ), resulting in increased peak and mean $\mathrm{P}_{\mathrm{aw}}$ and mean transpulmonary pressure (Ppeak, Pmean, and Ppl mean, respectively; Table 1), as well as reduced oxygenation and increased mean pulmonary artery pressure (Table 2).

\section{Assisted mechanical ventilation}

During $\mathrm{BIPAP}+\mathrm{SB}_{\text {mean }}$ we detected spontaneous breathing only on low but not on high continuous positive $\mathrm{P}_{\mathrm{aw}}$ levels. Minute ventilation did not differ between PSV and $\mathrm{BIPAP}+\mathrm{SB}_{\text {mean }}$ (Table 1). However, mean $\mathrm{V}_{\mathrm{T}}$ was higher, whereas mean RR was lower during PSV. Ppeak during $\mathrm{BIPAP}+\mathrm{SB}_{\text {controlled }}$ and PSV were comparable. The time spent during inspiration was proportionally shorter in $\mathrm{BIPAP}+\mathrm{SB}_{\text {mean }}$ than PSV, as reflected by Ti/Tot. Pmean during $\mathrm{BIPAP}+\mathrm{SB}_{\text {mean }}$ did not differ from PSV. However, Pmean and $\mathrm{Ppl}$ mean were higher during $\mathrm{BIPAP}+\mathrm{SB}_{\text {controlled }}$ and lower during BIPAP $+\mathrm{SB}_{\text {spont }}$ as compared with PSV. PEEP $_{i, \text { dyn }}$ values did not differ between assisted mechanical ventilation modes, but values of $\mathrm{P}_{0.1}$ and PTP were higher during BIPAP $+\mathrm{SB}_{\text {mean }}$ compared with PSV.

Arterial oxygenation and hemodynamic variables did not differ between the assisted mechanical ventilation modes, 
Table 1: Respiratory parameters

\begin{tabular}{|c|c|c|c|c|c|c|}
\hline & Baseline & Injury & PSV & $\mathrm{BIPAP}+\mathrm{SB}_{\text {mean }}$ & $\mathrm{BIPAP}+\mathrm{SB}_{\text {controlled }}$ & ${\mathrm{BIPAP}+\mathrm{SB}_{\text {spont }}}$ \\
\hline $\mathrm{MV}(\mathrm{L} / \mathrm{min})$ & $5.1 \pm 1.7$ & $4.1 \pm 1.7$ & $6.6 \pm 1.9$ & $6.2 \pm 2.1$ & $2.3 \pm 0.9^{t, \neq}$ & $4.0 \pm 2.2^{+, \neq, \S}$ \\
\hline $\mathrm{V}_{\mathrm{T}}(\mathrm{mL})$ & $347 \pm 58$ & $349 \pm 61$ & $202 \pm 48$ & $129 \pm 40^{+}$ & $255 \pm 103$ & $97 \pm 34^{t, \neq, \S}$ \\
\hline $\mathrm{RR}(/ \mathrm{min})$ & $15 \pm 4$ & $14 \pm 4$ & $34 \pm 11$ & $51 \pm 17^{\dagger}$ & $9 \pm 3^{+, \neq}$ & $43 \pm 17^{t, \neq, \S}$ \\
\hline $\mathrm{Ti} / \mathrm{Tt}$ tot & $0.49 \pm 0.01$ & $0.49 \pm 0.01$ & $0.33 \pm 0.05$ & -- & $0.24 \pm 0.08^{\dagger}$ & $0.26 \pm 0.06^{t, \neq}$ \\
\hline Ppeak $\left(\mathrm{cmH}_{2} \mathrm{O}\right)$ & $20 \pm 2$ & $34 \pm 3 *$ & $23 \pm 2$ & -- & $24 \pm 3$ & -- \\
\hline $\mathrm{P}_{\mathrm{aw}}$ mean $\left(\mathrm{cmH}_{2} \mathrm{O}\right)$ & $11 \pm 1$ & $15 \pm 1 *$ & $9 \pm 1$ & $9 \pm 1$ & $14 \pm 2^{t, \neq}$ & $5 \pm 1^{t, \neq, \S}$ \\
\hline Ppl mean $\left(\mathrm{cmH}_{2} \mathrm{O}\right)$ & $3 \pm 2$ & $7 \pm 2 *$ & $2 \pm 1$ & $2 \pm 1$ & $6 \pm 3^{t, 4}$ & $1 \pm 1^{t, \neq, \S}$ \\
\hline $\operatorname{PEEP}_{\mathrm{i}, \mathrm{dyn}}\left(\mathrm{cmH}_{2} \mathrm{O}\right)$ & -- & -- & $1 \pm 1$ & $1 \pm 1$ & -- & -- \\
\hline PTP $\left(\mathrm{cmH}_{2}\right.$ O.s.min $\left.{ }^{-1}\right)$ & -- & -- & $7 \pm 5$ & $91 \pm 54^{+}$ & -- & -- \\
\hline P0.1 $\left(\mathrm{cmH}_{2} \mathrm{O}\right)$ & -- & -- & $1 \pm 1$ & $3 \pm 1+$ & -- & -- \\
\hline
\end{tabular}

Values are given as mean \pm standard deviation; baseline, before induction of acute lung injury; injury, after induction of acute lung injury. The contributions of spontaneous and controlled

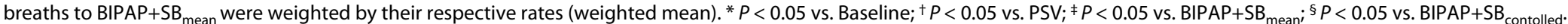

$\mathrm{BIPAP}+\mathrm{SB}_{\text {controlled, }}$, controlled breath cycles during BIPAP+SB $B_{\text {mean; }}$ BIPAP+SB $B_{\text {mean, }}$, biphasic positive airway pressure + spontaneous breathing; $\mathrm{BIPAP}+\mathrm{SB}$ spont, spontaneous breath cycles during $\mathrm{BIPAP}+\mathrm{SB}_{\text {spont }} ; \mathrm{MV}$, minute volume; $\mathrm{P}_{0.1}$, airway pressure generated $100 \mathrm{~ms}$ after onset of an occluded inspiratory effort; $\mathrm{P}_{\text {aw }}$ mean, mean airway pressure; $P$ PEEP $\mathrm{i}_{\mathrm{i} \text {,dyn, }}$ dynamic intrinsic end-

expiratory pressure; Ppeak, peak airway pressure; Ppl mean, mean transpulmonary pressure; PSV, pressure support ventilation; PTP, inspiratory esophageal pressure time product; RR, respiratory rate; $\mathrm{Ti} /$ Ttot, inspiratory to total respiratory time; $\mathrm{V}_{\mathrm{T}}$, tidal volume. 


\begin{tabular}{|c|c|c|c|c|}
\hline & Baseline & Injury & PSV & BIPAP+SB ${ }_{\text {mean }}$ \\
\hline \multicolumn{5}{|c|}{ Gas exchange } \\
\hline $\begin{array}{l}\mathrm{PaO}_{2} / \mathrm{FIO}_{2} \\
(\mathrm{mmHg})\end{array}$ & $\begin{array}{c}513 \pm 62 \\
(489.6-547.2)\end{array}$ & $\begin{array}{c}119 \pm 30^{*} \\
(92.0-143.1)\end{array}$ & $\begin{array}{c}264 \pm 127 \\
(136.0-378.7)\end{array}$ & $\begin{array}{c}246 \pm 112 \\
(143.1-332.5)\end{array}$ \\
\hline $\begin{array}{c}\mathrm{Q}_{\mathrm{VA}} / \mathrm{Q}_{\mathrm{t}} \\
(\%)\end{array}$ & $\begin{array}{l}5.5 \pm 1.4 \\
(4.4-6.5)\end{array}$ & $\begin{array}{c}33.9 \pm 12.8^{*} \\
(24.7-39.7)\end{array}$ & $\begin{array}{c}16.9 \pm 10.4 \\
(6.7-24.3)\end{array}$ & $\begin{array}{l}19.8 \pm 12.1 \\
(11.6-28.7)\end{array}$ \\
\hline $\begin{array}{l}\mathrm{PaCO}_{2} \\
(\mathrm{mmHg})\end{array}$ & $\begin{array}{c}34 \pm 6 \\
(29.4-39.7)\end{array}$ & $\begin{array}{c}39 \pm 8^{*} \\
(30.1-46.5)\end{array}$ & $\begin{array}{c}48 \pm 6 \\
(44.2-55.2)\end{array}$ & $\begin{array}{c}59 \pm 13^{\dagger} \\
(46.9-66.2)\end{array}$ \\
\hline \multicolumn{5}{|c|}{ Hemodynamics } \\
\hline $\begin{array}{l}\mathrm{CO} \\
(\mathrm{L} / \mathrm{min})\end{array}$ & $\begin{array}{l}3.2 \pm 0.8 \\
(2.4-3.8)\end{array}$ & $\begin{array}{c}3 \pm 0.8 \\
(2.3-3.8)\end{array}$ & $\begin{array}{l}4.3 \pm 1.4 \\
(2.8-5.3)\end{array}$ & $\begin{array}{l}4.2 \pm 1.2 \\
(3.2-5.2)\end{array}$ \\
\hline $\begin{array}{l}\mathrm{HR} \\
(/ \mathrm{min})\end{array}$ & $\begin{array}{l}77 \pm 13 \\
(69-83)\end{array}$ & $\begin{array}{l}75 \pm 12 \\
(65-86)\end{array}$ & $\begin{array}{l}91 \pm 18 \\
(83-100)\end{array}$ & $\begin{array}{l}91 \pm 19 \\
(77-110)\end{array}$ \\
\hline $\begin{array}{l}\text { MAP } \\
(\mathrm{mmHg})\end{array}$ & $\begin{array}{l}73 \pm 9 \\
(67-79)\end{array}$ & $\begin{array}{l}69 \pm 12 \\
(62-75)\end{array}$ & $\begin{array}{l}75 \pm 8 \\
(71-77)\end{array}$ & $\begin{array}{l}79 \pm 14 \\
(68-98)\end{array}$ \\
\hline $\begin{array}{l}\text { MPAP } \\
(\mathrm{mmHg})\end{array}$ & $\begin{array}{l}22 \pm 4 \\
(20-24)\end{array}$ & $\begin{array}{l}30 \pm 5^{*} \\
(27-32)\end{array}$ & $\begin{array}{l}31 \pm 5 \\
(26-35)\end{array}$ & $\begin{array}{c}33 \pm 6 \\
(30-36)\end{array}$ \\
\hline $\begin{array}{l}\text { CVP } \\
(\mathrm{mmHg})\end{array}$ & $\begin{array}{l}10 \pm 3 \\
(8-12)\end{array}$ & $\begin{array}{c}11 \pm 2 \\
(10-11)\end{array}$ & $\begin{array}{c}9 \pm 2 \\
(8-10)\end{array}$ & $\begin{array}{c}9 \pm 2 \\
(7-11)\end{array}$ \\
\hline $\begin{array}{l}\text { PCWP } \\
(\mathrm{mmHg})\end{array}$ & $\begin{array}{c}13 \pm 2 \\
(12-14)\end{array}$ & $\begin{array}{c}14 \pm 2 \\
(12-15)\end{array}$ & $\begin{array}{c}13 \pm 4 \\
(11-14)\end{array}$ & $\begin{array}{c}12 \pm 2 \\
(11-15)\end{array}$ \\
\hline \multicolumn{5}{|c|}{$\begin{array}{l}\text { Values are given as mean } \pm \text { standard deviation. Baseline, before induction of acute lung injury; injury, after induction of acute lung injury. }{ }^{*} \mathrm{P} \\
<0.05 \text { vs. baseline; }+\mathrm{P}<0.05 \text { vs. PSV. } \\
\mathrm{BIPAP}+\mathrm{SB}_{\text {mean }} \text {, biphasic positive airway pressure }+ \text { spontaneous breathing; } \mathrm{CO} \text {, cardiac output; } \mathrm{CVP} \text {, central venous pressure; FiO } \mathrm{F}_{2} \text {, fraction of } \\
\text { inspired oxygen; } \mathrm{HR} \text {, heart rate; } \mathrm{MAP} \text {, mean arterial pressure; } \mathrm{MPAP} \text {, mean pulmonary arterial pressure; } \mathrm{PaCO}_{2} \text {, partial pressure of arterial } \\
\text { carbon dioxide; } \mathrm{PaO} \mathrm{O}_{2} \text {, partial pressure of arterial oxygen; } \mathrm{PCWP} \text {, pulmonary artery occlusion pressure; } \mathrm{PSV} \text {, pressure support ventilation; }\end{array}$} \\
\hline
\end{tabular}

but $\mathrm{PaCO}_{2}$ was higher during $\mathrm{BIPAP}+\mathrm{SB}_{\text {mean }}$ than PSV (Table 2).

The statistical analysis evidenced no effect of the sequence of ventilation modes on the hyperaerated, normally aerated, poorly aerated, and nonaerated compartments at end-expiration. The Additional files 2 and 3 show $\mathrm{CT}_{\mathrm{dyn}}$ videos of lungs during $\mathrm{BIPAP}+\mathrm{SB}_{\text {mean }}$ and PSV in one animal, respectively.

During $\mathrm{BIPAP}+\mathrm{SB}_{\text {mean }}$ and PSV, we observed at endexpiration and end-inspiration (Figures 1 and 2, respectively) a gravity-dependent loss of lung aeration, characterized by increase of nonaerated and poorly aerated areas, as well as decrease in hyperaerated and normally aerated tissue in dorsal zones, as compared with ventral ones $(P<$ $0.0001)$. Similarly, the percentages of nonaerated and poorly aerated areas increased, whereas those from nor- mally aerated and hyperaerated areas decreased from lung apex to base following the gravitational gradient, independent from the assisted mechanical ventilation mode and lung zone $(P<0.0001)$.

Compared with PSV, BIPAP $+\mathrm{SB}_{\text {controlled }}$ and BIPAP $+\mathrm{SB}_{\mathrm{s}}$ pont resulted in a reduction of the percentage of nonaeration at end-expiration at the lung base (Figure 1, $P<0.05$ ). At end-inspiration, $\mathrm{BIPAP}+\mathrm{SB}_{\text {mean }}$ led to an increased percentage of normally aerated tissue at apex and hilum, as well as reduced poorly aerated and nonaerated tissue at apex and base, respectively, mainly during controlled breaths (Figure $2, P<0.05)$. The distribution of aeration during $\mathrm{BIPAP}+\mathrm{SB}_{\text {controlled }}$ and $\mathrm{BIPAP}+\mathrm{SB}_{\text {spont }}$ was comparable at end-expiration, as well as end-inspiration (Figures 1 and 2, respectively). 


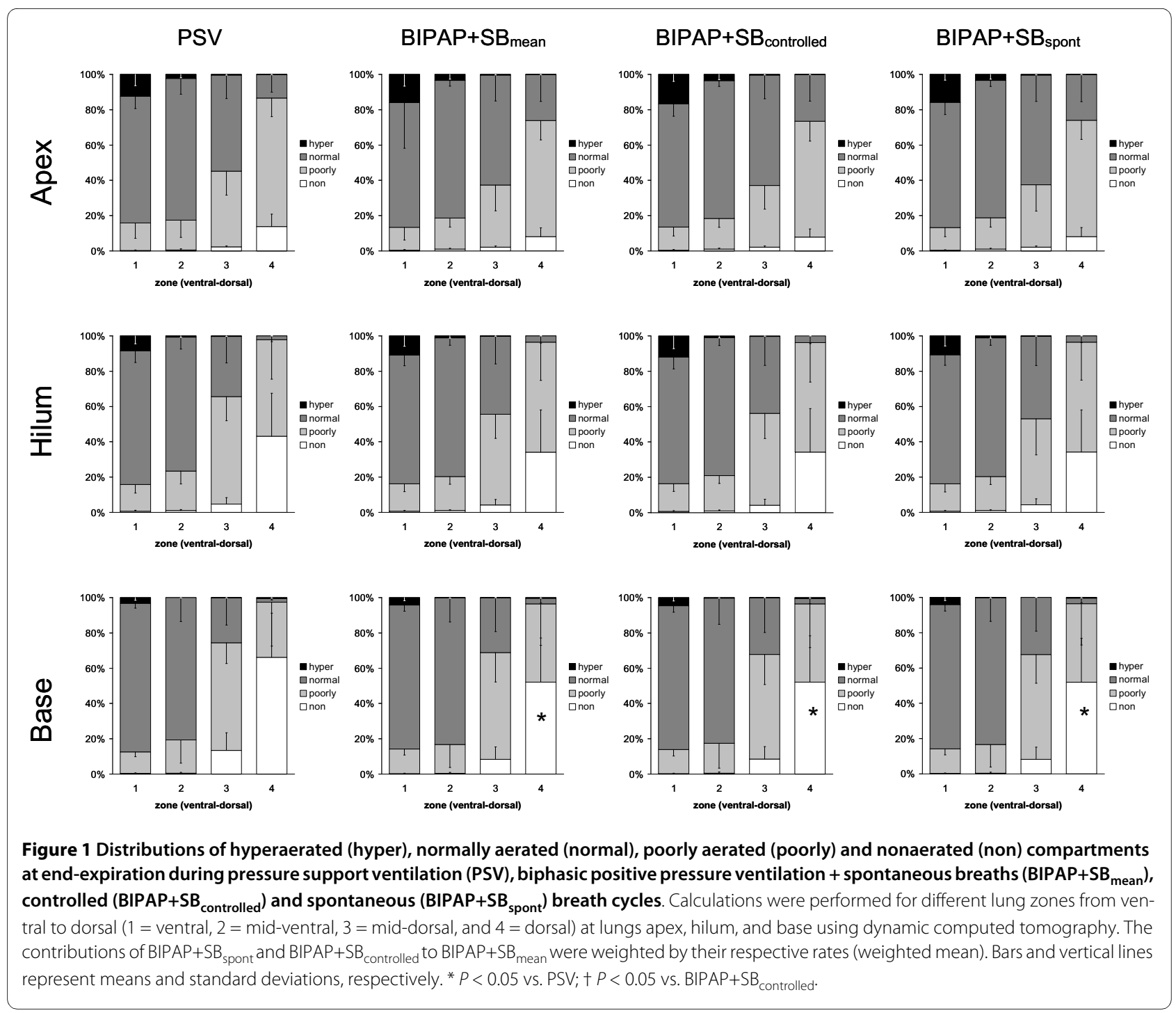

As shown in Figure 3, tidal reaeration had a gravitydependent pattern $(P<0.0001)$, increasing from ventral to mid-dorsal $(P<0.0001)$, but decreasing from mid-dorsal to dorsal zones $(P<0.0001)$. Compared with PSV, $\mathrm{BIPAP}+\mathrm{SB}_{\text {mean }}$ induced less tidal reaeration in mid-dorsal zones, mainly due to spontaneous breaths. Also, in dorsal zones, tidal reaeration was more pronounced during PSV than $\mathrm{BIPAP}+\mathrm{SB}_{\text {spont }}$. On the other hand, tidal reaeration was less marked during PSV than controlled breaths of $\mathrm{BIPAP}+\mathrm{SB}_{\text {mean }}$.

Tidal hyperaeration increased from dorsal to ventral lung zones, as well as from apex to base (Figure 4, $P<0.0001$ both). Tidal hyperaeration was decreased during $\mathrm{BIPAP}+\mathrm{SB}_{\text {mean }}$ compared with PSV. In ventral zones of the lung apex and base, tidal hyperaeration increased during controlled but decreased during BIPAP $+\mathrm{SB}_{\text {spont }}$ compared with PSV.
Distribution of ventilation did not differ among the lung levels, but was lowest in ventral and highest in mid-ventral zones $(P<0.0001$ both). No differences were observed among $\mathrm{PSV}, \mathrm{BIPAP}+\mathrm{SB}_{\text {mean }}, \mathrm{BIPAP}+\mathrm{SB}_{\text {controlled }}$ and $\mathrm{BIPAP}+\mathrm{SB}_{\text {spont }}(P=1.0)$.

\section{Discussion}

In a surfactant depletion model of ALI, we found that $\mathrm{BIPAP}+\mathrm{SB}_{\text {mean }}$ compared with PSV resulted in: lower mean $\mathrm{V}_{\mathrm{T}}$, comparable oxygenation and hemodynamics, and increased $\mathrm{PaCO}_{2}$ and inspiratory effort; less nonaerated areas at end-expiration; decreased tidal hyperaeration and reaeration; and similar distributions of relative ventilation. During $\mathrm{BIPAP}+\mathrm{SB}_{\text {mean }}$ : $\mathrm{BIPAP}+\mathrm{SB}_{\text {spont }}$ had lower $\mathrm{V}_{\mathrm{T}}$ and higher rate than $\mathrm{BIPAP}+\mathrm{SB}_{\text {controlled; }} \mathrm{BIPAP}+\mathrm{SB}_{\text {spont }}$ and $\mathrm{BIPAP}+\mathrm{SB}_{\text {controlled }}$ had similar distributions of ventilation and aeration; $\mathrm{BIPAP}+\mathrm{SB}_{\text {controlled }}$ resulted in increased tidal 


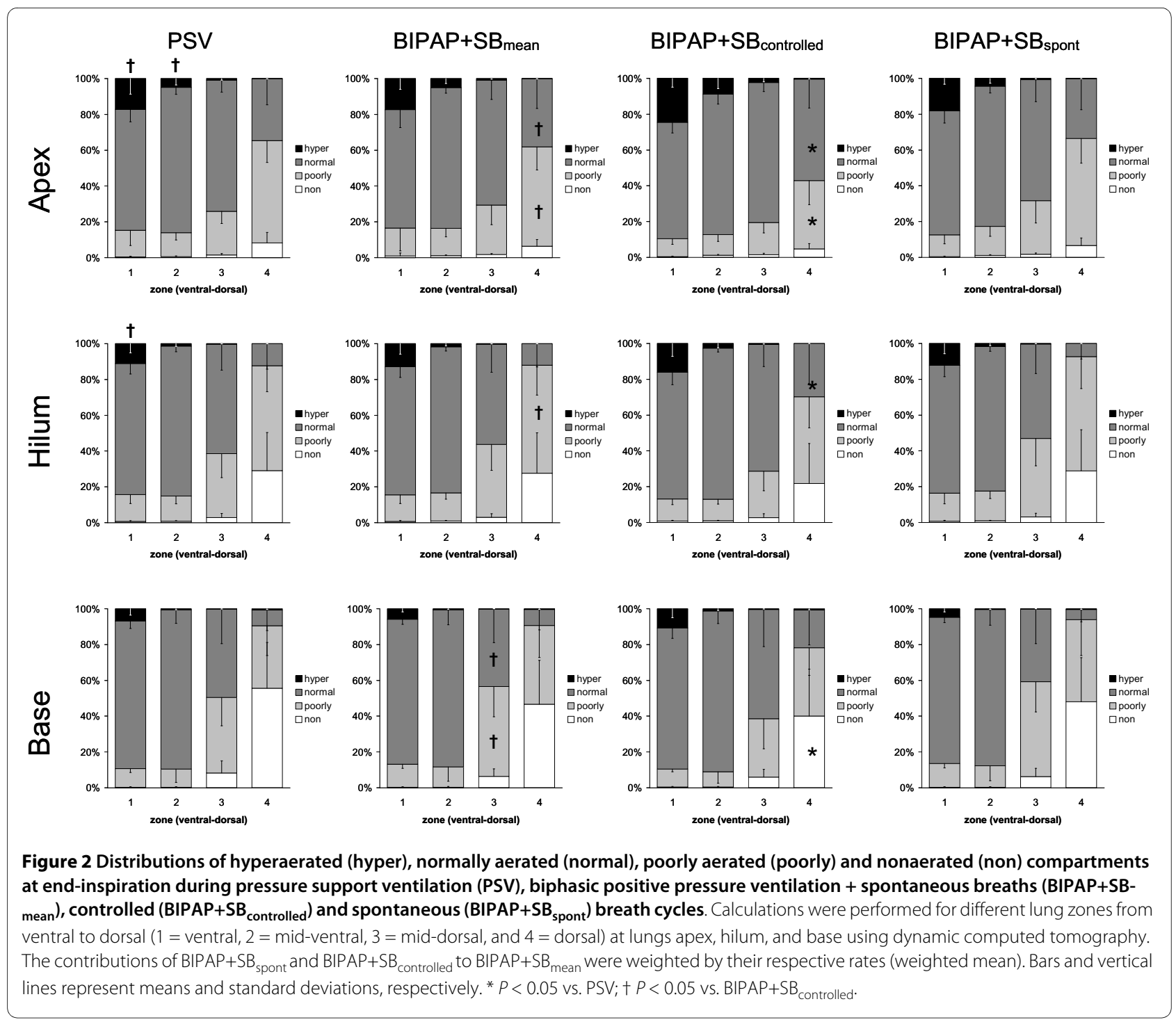

reaeration and hyperareation, compared with PSV. $\mathrm{BIPAP}+\mathrm{SB}_{\text {spont }}$ showed an opposite pattern.

To our knowledge, this is the first study showing that despite reduced nonaerated lung tissue during $\mathrm{BIPAP}+\mathrm{SB}_{\text {mean }}$ compared with PSV, differences in tidal reaeration and hyperaeration seem to be due only to lower $\mathrm{V}_{\mathrm{T}}$ of spontaneous breaths, because the distribution ventilation are comparable.

The present study differs from previous investigations on $\mathrm{BIPAP}+\mathrm{SB}_{\text {mean }}$ and PSV [6,9-11] in that: $\mathrm{CT}_{\text {dyn }}$ was used to assess regional aeration during up to 60 seconds; no breath holds at end-expiration or end-inspiration were used; and both the mean $\mathrm{P}_{\mathrm{aw}}$ and minute ventilation were comparable between BIPAP $+\mathrm{SB}_{\text {mean }}$ and PSV. Different investigators have used $\mathrm{CT}_{\text {dyn }}$ to quantify lung aeration, detect tidal recruitment and derecruitment, as well hyperaeration in ALI/acute respiratory distress syndrome (ARDS) $[8,16,17]$.
When negative intrapleural pressures are generated, $\mathrm{CT}_{\text {dyn }}$ seems to be superior to static helical CT for quantifying lung aeration at mid-expiration and mid-inspiration [18]. Furthermore, as $\mathrm{V}_{\mathrm{T}}$ during $\mathrm{BIPAP}+\mathrm{SB}_{\text {mean }}$ and $\mathrm{PSV}$ are not constant [19], aeration measurements taken within a single breath may be less representative of longer periods of ventilation.

\section{Aeration compartments}

Compared with PSV, BIPAP $+\mathrm{SB}_{\text {mean }}$ reduced the percentage of nonaerated areas at end-expiration in dependent lung zones, both BIPAP $+\mathrm{SB}_{\text {controlled }}$ and BIPAP $+\mathrm{SB}_{\text {spont }}$. At endinspiration, the patterns of distribution of aeration were similar between BIPAP $+\mathrm{SB}_{\text {mean }}$ and PSV. Nonetheless, $\mathrm{BIPAP}+\mathrm{SB}_{\text {controlled }}$ showed less poorly aerated and more normally aerated percentages of lung tissue than $\mathrm{BIPAP}+\mathrm{SB}_{\text {mean }}$. Two mechanisms can explain these obser- 


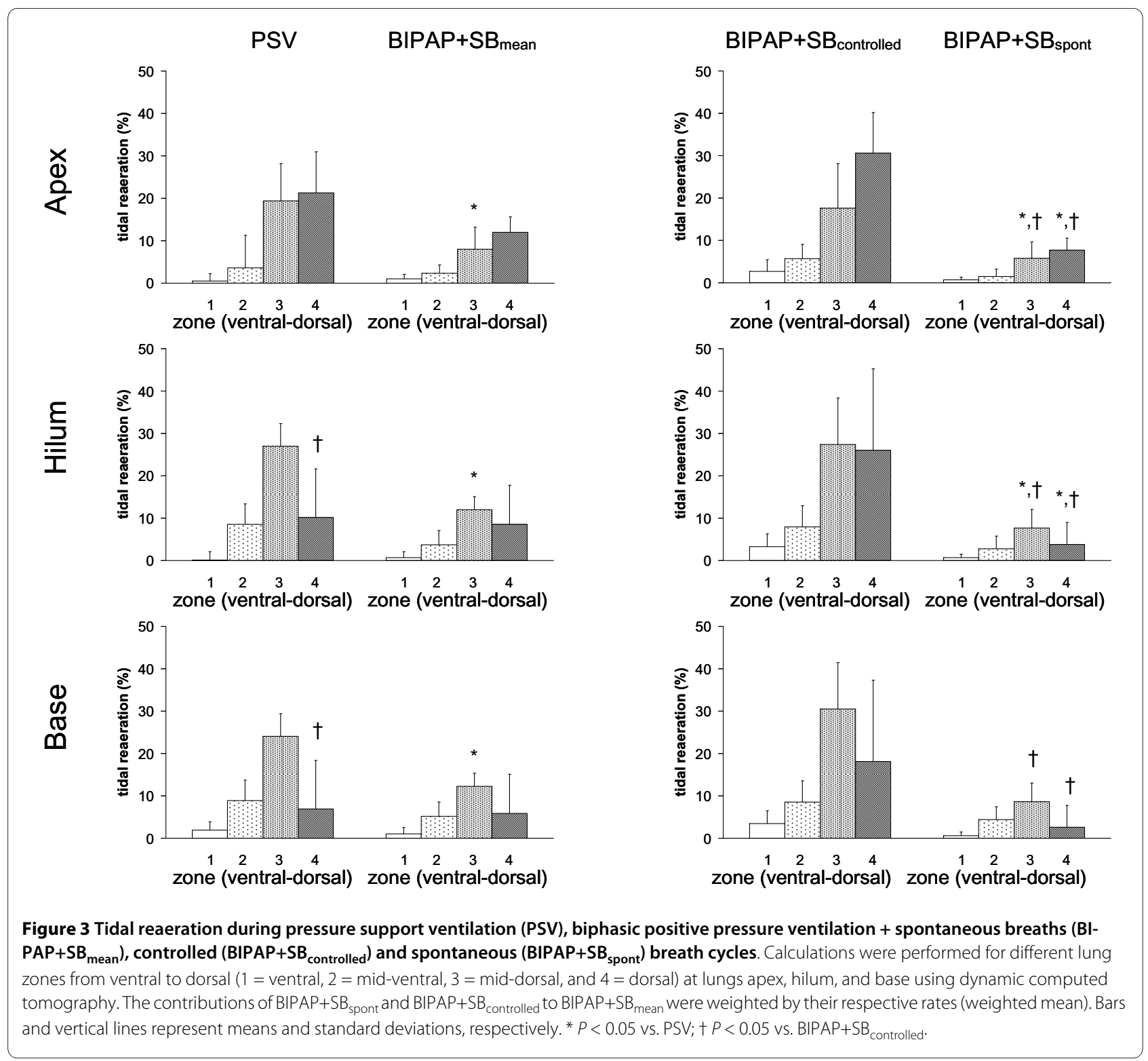

vations. First, spontaneous breathing may have favored recruitment of more dependent zones at end-expiration, with effects being preserved during controlled breaths. This hypothesis is supported by increased PTP and Ppl mean during $\mathrm{BIPAP}+\mathrm{SB}_{\text {mean }}$ compared with PSV. Second, $\mathrm{BIPAP}+\mathrm{SB}_{\text {controlled }}$ generated higher products of $\mathrm{P}_{\mathrm{aw}}$ in time during inspiration, as shown by our data, thus promoting recruitment of lung zones with increased time constants, with effects being preserved during $\mathrm{BIPAP}+\mathrm{SB}_{\text {spont }}$. Indeed, it has been shown that in controlled ventilation the more tissue is recruited at end-inspiration, the more tissue remains recruited at end-expiration [20]. On the other hand, the amount of hyperaeration at end-inspiration was higher during BIPAP+SB ${ }_{\text {controlled }}$ than PSV, despite comparable Ppeak. The most probable explanation is that Pmean was higher during $\mathrm{BIPAP}+\mathrm{SB}_{\text {controlled }}$ than PSV. Another likely explanation is that the gas volume at end-expiration was higher, as suggested by lower percentages of nonaerated areas during $\mathrm{BIPAP}+\mathrm{SB}_{\text {mean }}$, generating an overall shift towards more aeration. Accordingly, hyperaeration was more localized in non-dependent lung zones. However, mean hyperaeration at end-inspiration was comparable between $\mathrm{BIPAP}+\mathrm{SB}_{\text {mean }}$ and PSV, due to less hyperaeration during $\mathrm{BIPAP}+\mathrm{SB}_{\text {spont }}$.

\section{Tidal reaeration and hyperaeration}

Tidal recruitment or reaeration and tidal hyperaeration have been proposed to reflect the phenomena of cyclic collapse/ reopening and overdistension of lung units in ALI/ARDS $[14,21]$, which are important risk factors for ventilator- 


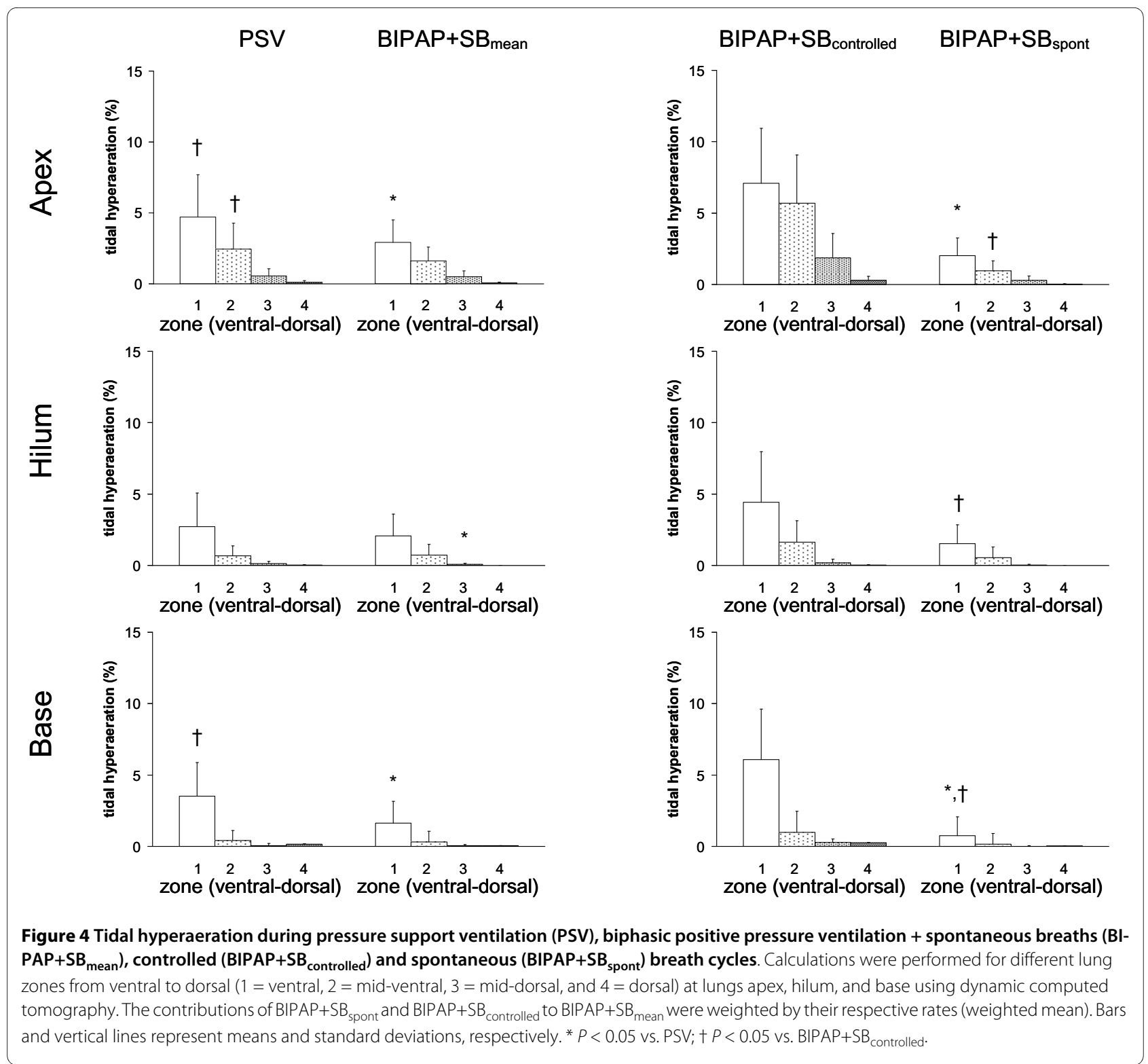

associated lung injury [22]. Recruitment occurs mainly in nonaerated tissue [21], but seems to also take place in the poorly aerated tissue [14]. Tidal reaeration and hyperaeration have been described during studies on controlled mechanical ventilation [14,21,23,24], but data during assisted mechanical ventilation are scarce. Wrigge and colleagues [8] reported in an oleic acid model of ALI, more aeration and less tidal recruitment in dependent lung zones during $\mathrm{BIPAP}+\mathrm{SB}_{\text {mean }}$ compared with pressure-controlled ventilation. However, other forms of assisted mechanical ventilation were not addressed. We found that mean tidal hyperaeration and reaeration were less pronounced during $\mathrm{BIPAP}+\mathrm{SB}$ than PSV. However, when analyzed separately, we found that BIPAP $+\mathrm{SB}_{\text {controlled }}$ were associated with increased tidal hyperaeration and reaeration compared with
$\mathrm{PSV}$, whereas BIPAP $+\mathrm{SB}_{\text {spont }}$ showed the opposite pattern. As mean $\mathrm{V}_{\mathrm{T}}$ and $\mathrm{Ppl}$ were lower during $\mathrm{BIPAP}+\mathrm{SB}_{\text {spont }}$ than $\mathrm{BIPAP}+\mathrm{SB}_{\text {controlled }}$ BIPAP $+\mathrm{SB}_{\text {mean }}$ could be claimed to be more lung protective than PSV due to lower mean distending volumes/pressures during spontaneous breathing. On the other hand, Plpl, tidal hyperaeration and reaeration were more pronounced during $\mathrm{BIPAP}+\mathrm{SB}_{\text {controlled }}$ than PSV. Thus, the phenomena of cyclic collapse-reopening and overdistension may be more significant if the proportion of controlled to spontaneous breaths during BIPAP $+\mathrm{SB}_{\text {mean }}$ is high. Furthermore, RR was higher during $\mathrm{BIPAP}+\mathrm{SB}_{\text {mean }}$ compared with PSV, which may favor lung injury [25]. Our findings raise the question on how much spontaneous breathing should be allowed or used during BIPAP $+\mathrm{SB}_{\text {mean }}$ to improve respiratory function and reduce ventilator-asso- 
ciated lung injury. However, it was beyond the scope of this work to determine the impact of BIPAP $+\mathrm{SB}_{\text {mean }}$ and PSV on lung injury.

\section{Distribution of ventilation and gas exchange}

As $\mathrm{BIPAP}+\mathrm{SB}_{\text {mean }}$ was associated with increased inspiratory effort, we expected the relative ventilation to be higher with that mode in the most dependent lung zones compared with PSV [26]. However, the distribution of ventilation was similar during $\mathrm{BIPAP}+\mathrm{SB}_{\text {mean }}$ and PSV, both during spontaneous and controlled breaths. The most likely explanation is that although the inspiratory transpulmonary pressures in dependent zones increased aeration during $\mathrm{BIPAP}+\mathrm{SB}_{\text {mean }}$ compared with PSV, the impedance to ventilation was likely to not be changed and shift of relative ventilation did not occur.

As the percentage of nonaerated areas was decreased during $\mathrm{BIPAP}+\mathrm{SB}_{\text {mean }}$ compared with $\mathrm{PSV}$, we expected an improvement in oxygenation. However $\mathrm{PaO}_{2} / \mathrm{FIO}_{2}$ and venous admixture were comparable between modes, suggesting that hypoxic vasoconstriction most likely played a role. $\mathrm{BIPAP}+\mathrm{SB}_{\text {mean }}$ results in increased redistribution of pulmonary blood flow from dorsal to ventral zones [11]. Two possible mechanisms may explain limited carbon dioxide exchange during $\mathrm{BIPAP}+\mathrm{SB}_{\text {mean }}$ compared with PSV, despite similar minute ventilation. First, total alveolar ventilation was reduced due low $\mathrm{V}_{\mathrm{T}}$ in spontaneous breaths. Second, during controlled breaths, higher dead space due to increased hyperaerated areas may have occurred.

\section{Limitations}

This study has several limitations. First, the surfactant depletion model does not reproduce all features of clinical ALI and extrapolation of our results to the clinical scenario is limited. Second, artifacts introduced by the cranial-caudal movement of lungs were not compensated during calculations of aeration by $\mathrm{CT}_{\mathrm{dyn}}$, and levels chosen for the slices may have slightly differed between ventilation modes. However, measurements were performed at three different lung levels and we did observe regional differences. Furthermore, the levels used for CT scans were referred to anatomical landmarks (carina), likely reducing such artifacts. Third, tidal aeration and hyperaeration calculations were of volumetric nature. As hyperaerated areas have proportionally low mass, the absolute amount of lung tissue undergoing cyclic hyperaeration may be reduced. On the other hand, the thresholds for CT compartments most likely resulted in underestimation of hyperaeration in ALI, but they correspond to those internationally recommended $[27,28]$. Fourth, the assessment of relative ventilation by changes in CT densities may have been skewed by movement of gas within structures with limited participation in gas exchange, like small airways. Nevertheless, stress/strain of those structures seems to play an important role in ventilator-induced lung injury [29]. Fifth, we did not determine the impact of BIPAP $+\mathrm{SB}_{\text {mean }}$ and PSV on lung mechanical stress and inflammation directly. However, in experimental ALI, tidal hyperaeration and reaeration seem to be closely related to overdistension and collapse/reopening of lung units, respectively $[12,14,30]$.

\section{Conclusions}

In this model of ALI, the reduction of tidal reaeration and hyperaeration during $\mathrm{BIPAP}+\mathrm{SB}_{\text {mean }}$ compared with PSV is not due to decreased nonaerated areas at end-expiration or different distribution of ventilation, but to lower $\mathrm{V}_{\mathrm{T}}$ during $\mathrm{BIPAP}+\mathrm{SB}_{\text {spont }}$.

\section{Key messages}

- Compared with PSV, BIPAP+SB ${ }_{\text {mean }}$ resulted in: lower mean $\mathrm{V}_{\mathrm{T}}$, comparable oxygenation and hemodynamics, and increased $\mathrm{PaCO}_{2}$ and inspiratory effort; less nonaerated areas at end-expiration; decreased tidal hyperaeration and reaeration; similar distributions of relative ventilation.

- During BIPAP+SB $\mathrm{S}_{\text {mean }}: \mathrm{BIPAP}+\mathrm{SB}_{\text {spont }}$ had lower $\mathrm{V}_{\mathrm{T}}$ and higher rate than $\mathrm{BIPAP}+\mathrm{SB}_{\text {controlled }} ; \mathrm{BIPAP}+\mathrm{SB}_{\text {spont }}$ and $\mathrm{BIPAP}+\mathrm{SB}_{\text {controlled }}$ had similar distributions of ventilation and aeration; $\mathrm{BIPAP}+\mathrm{SB}_{\text {controlled }}$ resulted in increased tidal reaeration and hyperareation, compared with PSV, while $\mathrm{BIPAP}+\mathrm{SB}_{\text {spont }}$ showed an opposite pattern.

- The ratio between spontaneous to controlled breaths could play an important role in reducing tidal reaeration and hyperaeration during $\mathrm{BIPAP}+\mathrm{SB}_{\text {mean }}$.

\section{Additional material}

\begin{abstract}
Additional file 1 Calculation of mean airway pressures. This file shows exactly how the mean airway pressures were calculated for the different modes of assisted ventilation, including the spontaneous and controlled cycles of biphasic positive airway pressure + spontaneous breathing $\left(\mathrm{BIPAP}+\mathrm{SB}_{\text {mean }}\right)$

Additional file 2 Dynamic computed tomography in a representative animal during biphasic positive airway pressure + spontaneous breathing (BIPAP+SB ${ }_{\text {mean }}$ ). This video shows a dynamic computed tomography scan (grey scale) of the chest taken for approximately $60 \mathrm{sec}-$ onds at the hilus in one representative animal during assisted ventilation with $\mathrm{BIPAP}+\mathrm{SB}_{\text {mean. }}$. Acute lung injury was induced by surfactant depletion. See Additional file 3 for comparison with pressure support ventilation (PSV). Additional file 3 Dynamic computed tomography in a representative animal during pressure support ventilation (PSV). This video shows a dynamic computed tomography scan (grey scale) of the chest taken for approximately 60 seconds at the hilus in a representative animal during assisted ventilation with PSV. Acute lung injury was induced by surfactant depletion. See Additional file 2 for comparison with biphasic positive airway pressure + spontaneous breathing $\left(\mathrm{BIPAP}+\mathrm{SB}_{\text {mean }}\right)$.
\end{abstract}

\section{Abbreviations}

ALl: acute lung injury; ARDS: acute respiratory distress syndrome; $\mathrm{BIPAP}+\mathrm{SB}_{\text {con- }}$ trolled: time-cycled controlled breaths at two levels of continuous positive air- 
way pressure during $\mathrm{BIPAP}+\mathrm{SB}_{\text {mean }}$ BIPAP+SB mean: biphasic positive airway pressure with non-assisted spontaneous breathing; $\mathrm{BIPAP}+\mathrm{SB}_{\text {spont }}$ : non-assisted spontaneous breathing during $\mathrm{BIPAP}+\mathrm{SB}_{\text {mean }} ; \mathrm{CT}$ : computed tomography; $\mathrm{CT}_{\text {dyn }}$ : dynamic computed tomography; $\mathrm{FiO}_{2}$ : fraction of inspired oxygen; $\mathrm{HU}$ : Hounsfield units; I:E: inspiratory:expiratory ratio; $\mathrm{P}_{0.1}$ : decay in airway pressure $100 \mathrm{~ms}$ after begin of the inspiration; $\mathrm{PaCO}_{2}$ : partial pressure of arterial carbon dioxide; $\mathrm{PaO}_{2}$ : partial pressure of arterial oxygen; $\mathrm{P}_{\text {aw }}$ : airway pressure; PEEP: positive end-expiratory pressure; PEEP $_{i, d y n}$ : dynamic intrinsic end-expiratory pressure; Pmean: mean airway pressure; Ppeak: peak airway pressure; Ppl mean: mean transpulmonary pressure; PSV: pressure support ventilation; PTP: pressure versus time product of the inspiratory esophageal pressure; RR: respiratory rate; $\mathrm{Ti} /$ toto: inspiratory to total respiratory time; $\mathrm{V}_{\mathrm{T}}$ : tidal volume.

\section{Competing interests}

The authors declare that they have no competing interests.

\section{Authors' contributions}

All authors made substantial contribution to the study design. MGA and MC drafted the manuscript and helped to perform the experiments. PM, ARC and CS helped to perform the experiments and contributed to drafting the manuscript. MC and VH developed the software for analysis of dynamic computed tomography scans and helped to draft the manuscript. BW performed the more complex multivariate statistical analysis and helped to draft the manuscript. All other authors revised the manuscript for important intellectual content. All authors approved the final version of the manuscript for publication.

\section{Acknowledgements}

This work was supported, in part, by a research grant of the European Society of Anaesthesiology (ESA), Brussels, Belgium. We are indebted to the students of the Pulmonary Engineering Group of the Department of Anesthesiology and Intensive Care Therapy, University Hospital Carl Gustav Carus, Technical University of Dresden, Germany, for their support during the experiments.

\section{Author Details}

1Pulmonary Engineering Group, Department of Anaesthesiology and Intensive Care Therapy, University Hospital Carl Gustav Carus, Technical University of Dresden, Fetscherstr. 74, 01307 Dresden, Germany, 2Department of Anaesthesiology and Intensive Care Therapy, University Hospital Carl Gustav Carus, Technical University of Dresden, Fetscherstr. 74, 01307 Dresden, Germany, IInstitute of Radiology, University Hospital Carl Gustav Carus, Technical University of Dresden, Fetscherstr. 74, 01307 Dresden, Germany, 4Institute of Medical Informatics and Biometry, Medical Faculty Carl Gustav Carus, Technical University of Dresden, Löscherstr. 18, 01309 Dresden, Germany , 5Department of Ambient, Health and Safety, University of Insubria, Servizio di Anestesia B, Ospedale di Circolo e Fondazione Macchi viale Borri 57, 21100 Varese, Italy and ${ }^{6}$ Clinical Sensoring and Monitoring, Department of Anaesthesiology and Intensive Care Therapy, University Hospital Carl Gustav Carus, Technical University of Dresden, Fetscherstr. 74, 01307 Dresden, Germany

Received: 21 September 2009 Revised: 29 December 2009 Accepted: 16 March 2010 Published: 16 March 2010

\section{References}

1. Putensen C, Hering R, Muders T, Wrigge H: Assisted breathing is better in acute respiratory failure. Curr Opin Crit Care 2005, 11:63-68.

2. Putensen C, Zech S, Wrigge H, Zinserling J, Stuber F, von Spiegel T, Mutz $\mathrm{N}$ : Long-term effects of spontaneous breathing during ventilatory support in patients with acute lung injury. Am J Respir Crit Care Med 2001, 164:43-49.

3. Esteban A, Ferguson ND, Meade MO, Frutos-Vivar F, Apezteguia C, Brochard L, Raymondos K, Nin N, Hurtado J, Tomicic V, González M, Elizalde J, Nightingale P, Abroug F, Pelosi P, Arabi Y, Moreno R, Jibaja M, D'Empaire G, Sandi F, Matamis D, Montañez AM, Anzueto A, VENTILA Group: Evolution of mechanical ventilation in response to clinical research. Am J Respir Crit Care Med 2008, 177:170-177.

4. Seymour CW, Frazer M, Reilly PM, Fuchs BD: Airway pressure release and biphasic intermittent positive airway pressure ventilation: Are they ready for prime time? J Trauma 2007, 62:1298-1309.
5. Chiumello D, Pelosi P, Calvi E, Bigatello LM, Gattinoni L: Different modes of assisted ventilation in patients with acute respiratory failure. Eur Respir J 2002, 20:925-933.

6. Putensen C, Mutz N, Putensen-Himmer G, Zinserling J: Spontaneous breathing during ventilatory support improves ventilation-perfusion distributions in patients with acute respiratory distress syndrome. Am J Respir Crit Care Med 1999, 159:1241-1248.

7. Wrigge H, Zinserling J, Neumann P, Defosse J, Magnusson A, Putensen C, Hedenstierna G: Spontaneous breathing improves lung aeration in oleic acid-induced lung injury. Anesthesiology 2003, 99:376-384.

8. Wrigge H, Zinserling J, Neumann P, Muders T, Magnusson A, Putensen C, Hedenstierna G: Spontaneous breathing with airway pressure release ventilation favors ventilation in dependent lung regions and counters cyclic alveolar collapse in oleic-acid-induced lung injury: a randomized controlled computed tomography trial. Crit Care 2005, 9:R780-R789.

9. Henzler D, Pelosi P, Bensberg R, Dembinski R, Quintel M, Pielen V, Rossaint $R$, Kuhlen R: Effects of partial ventilatory support modalities on respiratory function in severe hypoxemic lung injury. Crit Care Med 2006, 34:1738-1745.

10. Yoshida T, Rinka H, Kaji A, Yoshimoto A, Arimoto H, Myiaichi T, Kan M: The impact of spontaneous ventilation on distribution of lung aeration in patients with acute respiratory distress syndrome: airway pressure release ventilation versus pressure support ventilation. Anesth Analg 2009, 109:1892-1900

11. Gama de Abreu M, Spieth P, Pelosi P, Carvalho AR, Walter C, SchreiberFerstl A, Aikele P, Neykova B, Hübler M, Koch T: Noisy pressure support ventilation: A pilot study on a new assisted ventilation mode in experimental lung injury. Crit Care Med 2008, 36:818-827.

12. Carvalho AR, Spieth PM, Pelosi P, Vidal Melo MF, Koch T, Jandre FC, Giannella-Neto A, Gama de Abreu M: Ability of dynamic airway pressure curve profile and elastance for positive end-expiratory pressure titration. Intensive Care Med 2008, 34:2291-2299.

13. Puybasset L, Cluzel P, Gusman P, Grenier P, Preteux F, Rouby JJ, the CT Scan ARDS Study Group: Regional distribution of gas and tissue in acute respiratory distress syndrome. I. Consequences for lung morphology. Intensive Care Med 2000, 26:857-869.

14. Malbouisson LM, Muller JC, Constantin JM, LU Q, Puybasset L, Rouby JJ, the CT Scan ARDS Study Group: Computed tomography assessment of positive end-expiratory pressure-induced alveolar recruitment in patients with acute respiratory distress syndrome. Am J Respir Crit Care Med 2001, 163:1444-1450.

15. Lachmann B, Robertson B, Vogel J: In vivo lung lavage as an experimental model of the respiratory distress syndrome. Acta Anaesthesiol Scand 1980, 24:231-236.

16. Markstaller K, Karmrodt J, Doebrich M, Wolcke B, Gervais H, Weiler N, Thelen M, Dick W, Kauczor HU, Eberle B: Dynamic computed tomography: a novel technique to study lung aeration and atelectasis formation during experimental CPR. Resuscitation 2002, 53:307-313.

17. David M, Karmrodt J, Bletz C, David S, Herweling A, Kauczor HU, Markstaller K: Analysis of atelectasis, ventilated, and hyperinflated lung during mechanical ventilation by dynamic CT. Chest 2005, 128:3757-3770.

18. Helm E, Talakoub O, Grasso F, Engelberts D, Alirezaie J, Kavanagh BP, Babyn P: Use of dynamic CT in acute respiratory distress syndrome (ARDS) with comparison of positive and negative pressure ventilation. Eur Radiol 2009, 19:50-57.

19. Gama de Abreu M, Spieth P, Pelosi P, Carvalho AR, Walter C, SchreiberFerstl A, Aikele P, Neykova B, Hübler M, Koch T: Noisy pressure support ventilation: a pilot study on a new assisted ventilation mode in experimental lung injury. Crit Care Med 2008, 36:818-827.

20. Pelosi P, Goldner M, McKibben A, Adams A, Eccher G, Caironi P, Losappio S, Gattinoni L, Marini JJ: Recruitment and derecruitment during acute respiratory failure: an experimental study. Am J Respir Crit Care Med 2001, 164:122-130.

21. Gattinoni L, Pelosi P, Crotti S, Valenza F: Effects of positive end-expiratory pressure on regional distribution of tidal volume and recruitment in adult respiratory distress syndrome. Am J Respir Crit Care Med 1995, 151:1807-1814.

22. dos Santos CC, Slutsky A: The contribution of biophysical lung injury to the development of biotrauma. Annu Rev Physiol 2006, 68:585-618.

23. Lu Q, Malbouisson L, Mourgeon E, Goldstein I, Coriat P, Rouby JJ: Assessment of PEEP-induced reopening of collapsed lung regions in 
acute lung injury: are one or three $\mathrm{CT}$ sections representative of the entire lung? Intensive Care Med 2001, 27:1504-1510.

24. Terragni PP, Rosboch G, Tealdi A, Corno E, Menaldo E, Davini O, Gandini G, Herrmann P, Mascia L, Quintel M, Slutsky AS, Gattinoni L, Ranieri VM: Tidal hyperinflation during low tidal volume ventilation in acute respiratory distress syndrome. Am J Respir Crit Care Med 2007, 175:160-166.

25. Hotchkiss JR, Blanch L, Murias G, Adams AB, Olson DA, Wangesteen DO, Leo PH, Marini JJ: Effects of decreased respiratory frequency on ventilator-induced lung injury. Am J Respir Crit Care Med 2000, 161:463-468.

26. Putensen $\mathrm{C}$, Wrigge $\mathrm{H}$ : Clinical review: Biphasic positive airway pressure and airway pressure release ventilation. Crit Care 2004, 8:492-497.

27. Gattinoni L, Caironi P, Pelosi P, Goodman LR: What has computed tomography taught us about the acute respiratory distress syndrome? Am J Respir Crit Care Med 2001, 164:1701-1711.

28. Rouby JJ, Puybasset L, Nieszkowska A, Lu Q: Acute respiratory distress syndrome: lessons from computed tomography of the whole lung. Crit Care Med 2003, 31:S285-S295.

29. Jain M, Sznajder JI: Bench-to-bedside review: Distal airways in acute respiratory distress syndrome. Crit Care 2007, 11:206.

30. Carvalho AR, Jandre FC, Pino AV, Bozza FA, Salluh J, Rodrigues R, Ascoli FO, Giannella-Neto A: Positive end-expiratory pressure at minimal respiratory elastance represents the best compromise between mechanical stress and lung aeration in oleic acid induced lung injury. Crit Care 2007, 11:R86.

\section{doi: $10.1186 / \mathrm{cc} 8912$}

Cite this article as: Gama de Abreu et al, Regional lung aeration and ventilation during pressure support and biphasic positive airway pressure ventilation in experimental lung injury Critical Care 2010, 14:R34

\section{Submit your next manuscript to BioMed Centra} and take full advantage of:

- Convenient online submission

- Thorough peer review

- No space constraints or color figure charges

- Immediate publication on acceptance

- Inclusion in PubMed, CAS, Scopus and Google Scholar

- Research which is freely available for redistribution

Submit your manuscript at www.biomedcentral.com/submit
C Biomed Central 